\title{
MOLECULAR GENETICS OF BREAST AND OVARIAN CANCER: RECENT ADVANCES AND CLINICAL IMPLICATIONS
}

\author{
Bogdanova $\mathrm{N}^{1,2}$, Dörk $\mathrm{T}^{2, *}$
}

*Corresponding Author: Thilo Dörk, Ph.D., Hannover Medical School, Gynaecology Research Unit (OE 6411), Carl-Neuberg-Str. 1, D-30625 Hannover, Germany; Tel.: +49-511-532-6075; Fax: +49-511-5326081; E-mail: doerk.thilo@mh-hannover.de

\begin{abstract}
Over the last few years, evidence has been accumulated that several susceptibility genes exist that differentially impact on the lifetime risk for breast or ovarian cancer. High-to-moderate penetrance alleles have been identified in genes involved in DNA double-strand break signaling and repair, and many low-penetrance susceptibility loci have been identified through genome-wide association studies. In this review, we briefly summarize present knowledge about breast and ovarian cancer susceptibility genes and discuss their implications for risk prediction and therapy.
\end{abstract}

Keywords: Breast carcinoma, Ovarian carcinoma, Germ-line mutations, Chromosomal instability

\section{REVIEW}

Epidemiological and genetic linkage studies of mul-tiple-case families have guided the identification of $B R C A 1$ and $B R C A 2$ as the first genes in which mutations strongly predispose to breast and ovarian cancer. However, hereditary breast and ovarian cancer (HBOC) syndrome only represents

1 Clinic of Radiation Oncology, Hannover Medical School, Hannover, Germany

2 Clinic of Obstetrics and Gynaecology, Hannover Medical School, Hannover, Germany the extreme end of a wide spectrum of genetically influenced breast or ovarian carcinomas. During the last few years, evidence has been accumulated that several susceptibility genes exist [1-3]. Their mutations have differential impact according to the minor allele frequencies and the magnitude of the allelic effect. We briefly summarize our present knowledge about breast and ovarian cancer susceptibility genes and discuss their implications for risk prediction and therapy.

Rare Mutations With a High-to-Moderate Penetrance. $B R C A 1$ and $B R C A 2$ : The prototypic $B R C A 1$ and BRCA2 mutations confer a very high lifetime risk for breast cancer in the range of $55.0-85.0 \%$ for $B R C A 1$ and $35.0-60.0 \%$ for $B R C A 2$, compared with an about $10.0 \%$ general population risk. Mutations are usually truncating, although pathogenic missense mutations have also been described. Lifetime risk for ovarian cancer is also high and may be up to $40.0 \%$ for $B R C A 1$ mutation carriers. There seems to be allele-specific expressivity as some of the mutations appear to confer higher risks for ovarian cancer than others [4-6]. Both the risks for breast and ovarian cancer can also be modified by additional gene loci such as single nucleotide polymorphisms (SNPs) in RAD51 or $B N C 2[7,8]$ (see below).

The PALB2 Mutation. Subsequently, PALB2 has been identified as a breast cancer susceptibility gene $[9,10]$. The PALB2 protein bridges BRCA1 
and BRCA2 and synergizes in their function in recombinational DNA repair. Mutations in PALB2 predispose to breast cancer and gastric cancer, and the penetrance for breast cancer in Finnish multiplecase families has been found to be as high as for $B R C A 2$ mutations [11]. There is less evidence that $P A L B 2$ mutations may also constitute ovarian cancer susceptibility alleles. Although PALB2 founder mutations have been identified in ovarian cancer patients from Poland and Russia, they are still rare in these populations $[12,13]$.

The $\boldsymbol{R} \boldsymbol{A D 5 1}$ Paralogs. Downstream of BRCA1, BRCA2 and PALB2, the RAD51 protein is a key mediator of homologous recombination, and a regulatory variant c. $-98 \mathrm{G}>\mathrm{C}$ (also known as $135 \mathrm{G}>\mathrm{C}$ ) in $R A D 51$ acts as a genetic modifier of $B R C A 2$ mutations [7]. Mutation analyses in further genes of RAD51 paralogs have subsequently uncovered $R A D 51 C$ and $R A D 51 D$ as susceptibility genes for breast and ovarian cancer [14-16]. The initial data indicate that these mutations are specifically associated with a family history of ovarian cancer. However, mutations in RAD51C and RAD51D are collectively very rare and their penetrance and tumor spectrum remains to be fully explored.

Additional Fanconi Anemia Genes. Since some breast and ovarian cancer susceptibility alleles, e.g., in BRCA2, PALB2 or RAD51C, cause Fanconi anemia (FA) in the homozygous state, it seemed reasonable to assess further FA genes for their role in breast and ovarian cancer. So far, mutations of the BRIPI gene have been associated with breast cancer [17], although their precise risk estimates await further studies. There is no evidence implicating the FA core proteins in breast cancer, suggesting that proteins at the heart of the downstream homologous recombination machinery are the major factors for breast and ovarian cancer susceptibility.

Familial Lobular Breast Cancer. Familial lobular breast cancer has been associated with rare germ-line mutations in $C D H 1$, the gene for E-cadherin [18,19]. While mutations in $C D H 1$ are also causative for diffuse gastric cancer, there is no evidence to implicate $C D H 1$ in ovarian cancer yet.

Rare Syndromes Including Breast Cancer. Some rare syndromes include the occurrence of breast cancer as part of the disease spectrum. These include Li-Fraumeni (TP53), Muir-Torre Syndrome (MSH2), Cowden's Disease (PTEN), Peutz-Jeghers
Syndrome (LKBI), and Ataxia-telangiectasia (ATM, see below). Although these syndromes are generally rare, they need to be kept in mind if a breast cancer patient presents with a more complex disorder or family history.

Ataxia-Telangiectasia. Twenty-five years ago, it was shown that blood relatives of patients with the neurode-generative disorder ataxia-telangiectasia (A-T) face an increased breast cancer risk [20]. The gene mutated in ataxia-telangiectasia, ATM, encodes a master protein kinase that orchestrates the cellular response to DNA double-strand breaks and controls, via phosphorylation, hundreds of proteins involved in cell cycle control, repair and apoptosis, among them BRCA1, BRCA2, TP53, CHEK2 and many other tumor suppressors [21]. Truncating mutations in ATM appear to confer an about 3-fold increased breast cancer risk to heterozygous carriers [22-24]. While the homozygous condition of A-T is rare, heterozygotes may account for $0.5-1.0 \%$ of the population.

MRE11A/RAD50/NBN. Chromosome breaks are sensed and the ATM protein is activated via the MRN complex consisting of the proteins MRE11A, RAD50, and NBN. The NBN gene underlies Nijmegen Breakage Syndrome (NBS), which is most prevalent in Eastern Europe due to a Slavic founder mutation. While biallelic mutations cause NBS, heterozygous carriers face an about 3-5 fold increased breast cancer risk [25-27]. Similarly, biallelic mutations in $R A D 50$ give rise to a NBSlike disorder, whereas heterozygotes for a Finnish founder mutation are predisposed towards breast cancer [28]. MRE11A also is a gene for an A-Tlike disorder, although there has been only one study to associate MRE11A mutations with breast cancer so far [29]. None of the three genes have been extensively investigated in ovarian cancer, but germ-line mutations in any of them were identified in a recent large sequencing study [30].

$\boldsymbol{C H E K 2}$. Checkpoint kinase 2 is a major target of ATM and itself phosphorylates further tumor suppressor proteins, including p53 and BRCA1, in response to DNA damage [31]. CHEK2 had initially been found mutated in Li-Fraumeni patients and one of these mutations, $1100 \mathrm{delC}$, has subsequently been associated with familial breast cancer [32,33]. Heterozygous carriers for 1100delC have been reported with a 2- to 3 -fold increase in breast cancer 
risk [34], with rare homozygotes being found at much higher risk [35]. In Eastern Europe, two further truncating mutations IVS-II-1 $(\mathrm{G}>\mathrm{A})$ and CHEK2dele9,10 $(5 \mathrm{~kb})$ have been associated with at least similarly high breast cancer risks, whereas the missense mutation p.I157T has a lower penetrance $[25,36,37]$. There has not been conclusive evidence for a strong association of CHEK2 mutations with ovarian cancer, but their association with additional malignancies suggests a more general role in cancer predisposition [38].

Polymorphic Variants With Low Penetrance. Several polymorphic loci are known today that influence the risk of breast and/or ovarian cancer. This has been achieved through genome-wide association studies (GWAS) of SNPs by large consortia during the past 5 years. The published GWAS efforts have so far uncovered over 20 genomic loci for breast cancer [39-45] and six loci for serous epithelial ovarian cancer [46-48] at a genome-wide significance level. All these loci harbor low-penetrance alleles with allelic odds ratios of less than 1.5. As these loci still explain only a small part of the heritable fraction and further largescale studies are presently underway, it is likely that these numbers will increase very rapidly. Most of the hitherto identified loci appear to be specific for either breast or ovarian carcinomas. For example, the gene for fibroblast growth factor receptor 2, FGFR2 [39], harbors variants associated with breast but not ovarian cancer, and the gene for basonuclin-2, $B N C 2$ [46], harbors variants associated with ovarian but not breast cancer. Nevertheless, there is a minor group of shared loci that appear to influence both breast and ovarian cancer risk. Such genes include $B A B A M 1$ (encoding a BRCA1 binding partner also known as MERIT40), TERT (encoding a component of telomerase), and the protooncogene $M Y C$ on chromosome 8q24. Interestingly, a closer inspection of the $8 \mathrm{q} 24$ locus indicated that the associations with either breast or ovarian cancer were caused by independent variants at the same locus which may be explained by tissue-specific regulation of gene expression [49]. As a caveat, a GWAS roughly localizes but does not identify the causal variant, and in several cases, there is more than one candidate gene in the region spanned by the associated linkage disequilibrium block or under putative regulatory control of the identified locus. Fine-mapping approaches in different ethnic populations and gene expression studies are presently being used to further trace down the true predisposing gene variants. Copy number variants have also been investigated in a GWAS but this did not detect a significant association for breast cancer [50].

Implications for Risk Prediction and Therapy. The identification of mutations in individuals from families with HBOC makes it possible to predict the age-dependent risk for different cancers, including recurrence risks in the already affected, and to appropriately counsel the patient and her blood relatives. This may lead to an increased surveillance or targeted prevention including medication (such as tamoxifen) or preventive surgery (such as prophylactic oophorectomy). In many countries, this is available to patients with an over $35.0 \%$ lifetime risk such as $B R C A 1$ or $B R C A 2$, and possibly $P A L B 2$ mutation carriers, whereas a more restrained position is taken for patients with moderate-penetrance mutations conferring an about 3 -fold increase in breast cancer risk such as $A T M$ or CHEK2. Although it might also be suggested that for these mutations, the female carriers should benefit from increased surveillance, large studies on the efficacy of such measures are still lacking. No further consequences are considered for patients carrying common risk alleles at polymorphic loci, as these risks are too small individually to be clinically meaningful. With the identification of many more low-risk loci, however, it may become possible to calculate combinatorial risks that could be useful in a stratified approach for cancer prevention in the future $[51,52]$.

Identifying the genetic basis of breast or ovarian cancer in the individual patient might have further prognostic and therapeutic implications. For a long time, breast cancer therapy has been guided by the presence or absence of gene products such as hormone receptors or HER2/neu. Such gene expression profiles are partly determined by germline mutations such as BRCA1 mutations which are frequently associated with triple-negative breast cancers [53], but breast cancer pathology also seems to be influenced by low-penetrance variants such as in FGFR2, which is strongly associated with estrogen-receptor positive disease [54]. Studies are presently underway to investigate whether SNP 
profiling could thus be of prognostic value, and there are new drugs being developed that target additional breast cancer pathways such as those mediated by fibroblast growth factor receptors [55]. Recent reports further indicate that the outcome of ovarian cancer therapy is significantly influenced by the $B R C A 1 / B R C A 2$ mutational status. In these multi-center studies, mutation carriers showed an improved survival, probably due to a higher benefit from the usually applied platinum-based therapy that activates a DNA repair pathway defective in BRCA1 or BRCA2 deficient tumors [56]. Another recent approach to improve targeted therapy is based on the concept of "synthetic lethality" as exemplified by the introduction of PARP1 inhibitors into breast and ovarian cancer treatment of patients with $B R C A 1$ or $B R C A 2$ mutations, and probably beyond [57]. Here, the idea is to inhibit a repair pathway that can still be compensated by backup pathways in normal but not tumor cells. The apparent success of this concept has stimulated the targeting of other repair pathways in parallel to those known to be defective in breast or ovarian carcinomas. For example, inhibition of ATR, which is a backup kinase of ATM, has been reported to be particularly effective in tumors with TP53 or ATM mutations [58]. Though promising, such substances still need further development until they can be tested in clinical practice. It is the hope that with many more genes identified, a deeper understanding of breast and ovarian cancer development and progression, together with the ability of gene-based stratification, will ultimately lead to an improved and individually tailored therapy for the benefit of each patient.

\section{REFERENCES}

1. Turnbull C, Rahman N. Genetic predisposition to breast cancer: past, present, and future. Annu Rev Genomics Hum Genet. 2008; 9: 321-345.

2. Ghoussaini M, Pharoah PD. Polygenic susceptibility to breast cancer: current state-of-the-art. Future Oncol. 2009; 5(5): 689-701.

3. Gayther SA, Pharoah PD. The inherited genetics of ovarian and endometrial cancer. Curr Opin Genet Dev. 2010; 20(3): 231-238.

4. Risch HA, McLaughlin JR, Cole DE, et al. Prevalence and penetrance of germline BRCA1 and BRCA2 mutations in a population series of 649 women with ovarian cancer. Am J Hum Genet. 2001; 68(3): 700710.

5. Thompson D, Easton D, Breast Cancer Linkage Consortium. Variation in cancer risks, by mutation position, in BRCA2 mutation carriers. Am J Hum Genet. 2001; 68(2): 410-419.

6. Bogdanova NV, Antonenkova NN, Rogov YI, Karstens JH, Hillemanns P, Dörk T. High frequency and allele-specific differences of BRCA1 founder mutations in breast cancer and ovarian cancer patients from Belarus. Clin Genet. 2010; 78(4): 364-372.

7. Antoniou AC, Sinilnikova OM, Simard J, et al. RAD51 135G $>$ C modifies breast cancer risk among BRCA2 mutation carriers: results from a combined analysis of 19 studies. Am J Hum Genet. 2007; 81(6): 1186-1200.

8. Ramus SJ, Kartsonaki C, Gayther SA, Pharoah PD, Sinilnikova OM, Beesley J. Genetic variation at 9p22.2 and ovarian cancer risk for BRCA1 and BRCA2 mutation carriers. J Natl Cancer Inst. 2011; 103(2): 105-116.

9. Rahman N, Seal S, Thompson D, et al. PALB2, which encodes a BRCA2-interacting protein, is a breast cancer susceptibility gene. Nat Genet. 2007; 39(2): 165-167.

10. Erkko H, Xia B, Nikkilä J, et al. A recurrent mutation in PALB2 in Finnish cancer families. Nature. 2007; 446(7133): 316-319.

11. Erkko H, Dowty JG, Nikkilä J, et al. Penetrance analysis of the PALB2 c.1592delT founder mutation. Clin Cancer Res 2008;14(14):4667-4671.

12. Dansonka-Mieszkowska A, Kluska A, Moes J, et al. A novel germline PALB2 deletion in Polish breast and ovarian cancer patients. BMC Med Genet. 2010; 11: 20 .

13. Prokofyeva D, Bogdanova N, Bermisheva M, et al. Rare occurrence of PALB2 mutations in ovarian cancer patients from the Volga-Ural region. Clin Genet. 2012; 82(1): 100-101.

14. Meindl A, Hellebrand H, Wiek C, et al. Germline mutations in breast and ovarian cancer pedigrees establish RAD51C as a human cancer susceptibility gene. Nat Genet. 2010; 42(5): 410-414.

15. Pelttari LM, Heikkinen $\mathrm{T}$, Thompson $\mathrm{D}$, et al. RAD51C is a susceptibility gene for ovarian cancer. Hum Mol Genet. 2011; 20(16): 3278-3288.

16. Loveday C, Turnbull C, Ramsay E, Hughes D, Ruark E, Frankum JR. Germline mutations in RAD51D confer susceptibility to ovarian cancer. Nat Genet. 2011; 43(9): 879-882.

17. Seal S, Thompson D, Renwick A, et al. Truncating mutations in the Fanconi anemia J gene BRIP1 are low-penetrance breast cancer susceptibility alleles. Nat Genet. 2006; 38(11): 1239-1241. 
18. Masciari S, Larsson N, Senz J, et al. Germline E-cadherin mutations in familial lobular breast cancer. J Med Genet. 2007; 44(11): 726-731.

19. Xie ZM, Li LS, Laquet C, et al. Germline mutations of the E-cadherin gene in families with inherited invasive lobular breast carcinoma but no diffuse gastric cancer. Cancer. 2011; 117(14): 3112-3117.

20. Swift M, Reitnauer PJ, Morrell D, Chase CL. Breast and other cancers in families with ataxiatelangiectasia. N Engl J Med. 1987; 316(21): 12891294.

21. Shiloh Y. ATM and related protein kinases: safeguarding genome integrity. Nat Rev Cancer. 2003; 3(3): 155-168.

22. Renwick A, Thompson D, Seal S, et al. ATM mutations that cause ataxia-telangiectasia are breast cancer susceptibility alleles. Nat Genet. 2006; 38(8): 873-875.

23. Pylkäs K, Tommiska J, Syrjäkoski K, et al. Evaluation of the role of Finnish ataxia-telangiectasia mutations in hereditary predisposition to breast cancer. Carcinogenesis. 2007; 28(5): 1040-1045.

24. Bogdanova N, Cybulski C, Bermisheva M, et al. A nonsense mutation (E1978X) in the ATM gene is associated with breast cancer. Breast Cancer Res Treat. 2009; 118(1): 207-211.

25. Górski B, Cybulski C, Huzarski T, et al. Breast cancer predisposing alleles in Poland. Breast Cancer Res Treat. 2005; 92(1): 19-24.

26. Steffen J, Nowakowska D, Niwinska A, et al. Germline mutations $657 \mathrm{del} 5$ of the NBS1 gene contribute significantly to the incidence of breast cancer in Central Poland. Int J Cancer. 2006; 119(2): 472-475.

27. Bogdanova N, Feshchenko S, Schürmann $\mathrm{P}$, et al. Nijmegen Breakage Syndrome mutations and risk of breast cancer. Int J Cancer. 2008; 122(4): 802-806.

28. Heikkinen K, Rapakko K, Karppinen SM, et al. RAD50 and NBS1 are breast cancer susceptibility genes associated with genomic instability. Carcinogenesis. 2006; 27(8): 1593-1599.

29. Bartkova J, Tommiska J, Oplustilova L, et al. Aberrations of the MRE11-RAD50-NBS1 DNA damage sensor complex in human breast cancer: MRE11 as a candidate familial cancer-predisposing gene. Mol Oncol. 2008; 2(4): 296-316.

30. Walsh T, Casadei S, Lee MK, et al. Mutations in 12 genes for inherited ovarian, fallopian tube, and peritoneal carcinoma identified by massively parallel sequencing. Proc Natl Acad Sci USA. 2011; 108(44): 18032-18037.

31. Nevanlinna H, Bartek J. The CHEK2 gene and inherited breast cancer susceptibility. Oncogene. 2006; 25(43): 5912-5919.
32. Meijers-Heijboer H, van den Ouweland A, Klijn $\mathrm{J}$, et al; CHEK2-Breast Cancer Consortium. Lowpenetrance susceptibility to breast cancer due to CHEK2 $(*) 1100$ delC in noncarriers of BRCA1 or BRCA2 mutations. Nat Genet. 2002; 31(1): 55-59.

33. Vahteristo P, Bartkova J, Eerola H, et al. A CHEK2 genetic variant contributing to a substantial fraction of familial breast cancer. Am J Hum Genet. 2002; 71(2): 432-438.

34. CHEK2 Breast Cancer Case-Control Consortium. CHEK2*1100delC and susceptibility to breast cancer: a collaborative analysis involving 10,860 breast cancer cases and 9,065 controls from 10 studies. Am J Hum Genet. 2004; 74(6): 1175-1182.

35. Adank MA, Jonker MA, Kluijt I, et al. CHEK2* 1100delC homozygosity is associated with a high breast cancer risk in women. J Med Genet. 2011; 48(12): 860-863.

36. Cybulski C, Wokołorczyk D, Huzarski T, et al. A deletion in CHEK2 of 5,395 bp predisposes to breast cancer in Poland. Breast Cancer Res Treat. 2007; 102(1): 119-122.

37. Bogdanova N, Enssen-Dubrowinskaja N, Feshchenko S, et al. Association of two mutations in the CHEK2 gene with breast cancer. Int J Cancer. 2005; 116(2): 263-266.

38. Cybulski C, Górski B, Huzarski T, et al. CHEK2 is a multiorgan cancer susceptibility gene. Am J Hum Genet. 2004; 75(6): 1131-1135.

39. Easton DF, Pooley KA, Dunning AM, et al. Genomewide association study identifies novel breast cancer susceptibility loci. Nature. 2007; 447(7148): 1087-1093.

40. Ahmed S, Thomas G, Ghoussaini M, et al. Newly discovered breast cancer susceptibility loci on 3 p24 and 17q23.2. Nat Genet. 2009; 41(5): 585-590.

41. Antoniou AC, Wang X, Fredericksen ZS, et al. A locus on $19 \mathrm{p} 13$ modifies risk of breast cancer in BRCA1 mutation carriers and is associated with hormone receptor-negative breast cancer in the general population. Nat Genet 2010;42(10):885-892.

42. Turnbull C, Ahmed S, Morrison J, et al. Genomewide association study identifies five new breast cancer susceptibility loci. Nat Genet. 2010; 42(6): 504-507.

43. Haiman CA, Chen GK, Vachon CM, et al. A common variant at the TERT-CLPTM1L locus is associated with estrogen receptor-negative breast cancer. Nat Genet. 2011; 43(12): 1210-1214.

44. Long J, Cai Q, Sung $\mathrm{H}$, et al. Genome-wide association study in East Asians identifies novel susceptibility loci for breast cancer. PLoS Genet. 2012; 8(2): e1002532.

45. Ghoussaini M, Fletcher O, Michailidou K, et al. Genome-wide association analysis identifies three 
new breast cancer susceptibility loci. Nat Genet. 2012; 44(3): 312-318.

46. Song H, Ramus SJ, Tyrer J, et al. A genome-wide association study identifies a new ovarian cancer susceptibility locus on 9p22.2. Nat Genet. 2009; 41(9): 996-1000.

47. Goode EL, Chenevix-Trench G, Song H, et al. A genome-wide association study identifies susceptibility loci for ovarian cancer at $2 \mathrm{q} 31$ and 8q24. Nat Genet. 2010; 42(10): 874-879.

48. Bolton KL, Tyrer J, Song H, et al. Common variants at 19 p13 are associated with susceptibility to ovarian cancer. Nat Genet. 2010; 42(10): 880-884.

49. Ghoussaini M, Song H, Koessler T, et al. Multiple loci with different cancer specificities within the 8 q24 gene desert. J Natl Cancer Inst. 2008; 100(13): 962-966.

50. Wellcome Trust Case Control Consortium. Genomewide association study of CNVs in 16,000 cases of eight common diseases and 3,000 shared controls. Nature. 2010; 464(7289): 713-720.

51. Pharoah PD, Antoniou AC, Easton DF, Ponder BA. Polygenes, risk prediction, and targeted prevention of breast cancer. N Engl J Med. 2008; 358(26): 27962803.

52. Pashayan N, Duffy SW, Chowdhury S, et al. Polygenic susceptibility to prostate and breast cancer: implications for personalised screening. $\mathrm{Br} \mathrm{J}$ Cancer. 2011; 104 (10): 1656-1663.
53. Robertson L, Hanson H, Seal S, et al. BRCA1 testing should be offered to individuals with triple-negative breast cancer diagnosed below 50 years. Br J Cancer. 2012; 106(6): 1234-1238.

54. Broeks A, Schmidt MK, Sherman ME, et al. Low penetrance breast cancer susceptibility loci are associated with specific breast tumor subtypes: findings from the Breast Cancer Association Consortium. Hum Mol Genet. 2011; 20(16): 32893303.

55. Hynes NE, Dey JH. Potential for targeting the fibroblast growth factor receptors in breast cancer. Cancer Res. 2010; 70(13): 5199-5202.

56. Bolton KL, Chenevix-Trench $\mathrm{G}$, Goh $\mathrm{C}$, et al. Association between BRCA1 and BRCA2 mutations and survival in women with invasive epithelial ovarian cancer. JAMA. 2012; 307(4): 382-390.

57. Dedes KJ, Wilkerson PM, Wetterskog D, Weigelt B, Ashworth A, Reis-Filho JS. Synthetic lethality of PARP inhibition in cancers lacking BRCA1 and BRCA2 mutations. Cell Cycle. 2011; 10(8): 11921199.

58. Reaper PM, Griffiths MR, Long JM, et al. Selective killing of ATM- or p53-deficient cancer cells through inhibition of ATR. Nat Chem Biol. 2011; 7(7): 428430. 